\title{
116. Photolysis of Dinitrophenyl-Amino Acids
}

\author{
By Shiro Akabori, Tokuji Ikenaka, Yoshimi Okada, \\ and Keiichi KoHNo
}

Laboratory of Biochemistry, Faculty of Science, Osaka University

(Comm. by R. MaJima, M.J.A., Nov. 12, 1953)

The 2,4-dinitrophenyl (DNP)-derivative method introduced by Sanger ${ }^{1)}$ has been used by many workers for the identification and determination of amino terminal groups of proteins and peptides. It has been pointed out by Sanger ${ }^{2)}$, Blackburn ${ }^{3)}$, and Mills ${ }^{4)}$, that DNP-amino acids are unstable in the light on the silicagel column and in chloroform, and that DNP-amino acids or peptides should be dissolved or suspended in dilute hydrochloric acid and kept in the dark. There are, however, no reports on the quantitative experiments on the photolysis of DNP-amino acids.

In the course of our studies on the terminal groups of proteins we also found that most of DNP-amino acids are very sensitive to light in dilute aqueous solution and wish to call attention of protein chemists on this fact.

The present note is the results of our semiquantitative experiments on the photochemical decomposition of various DNP-amino acids. The results obtained are represented in Fig. 1.

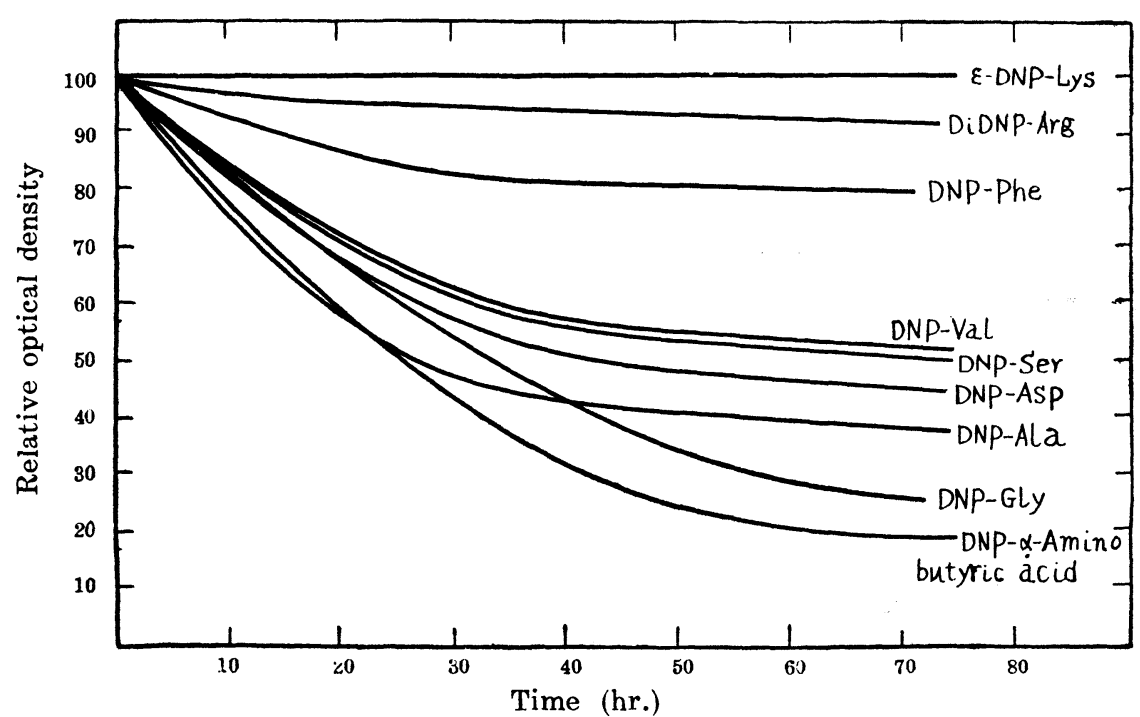

Fig. 1. Decolortion curve of DNP-amio acids by light. $0.1 \mathrm{mmol}$ aqueous solution of DNP-amino acids was exposed to a $200 \mathrm{~W}$ bulb at distance of $30 \mathrm{~cm}$. Color densities were measured with a photoelectric colorimeter using a filter $(430 \mathrm{~m} \mu)$. 
The decrease in color density is not proportional to the degree of the decomposition because by the photolysis of DNP-amino acids some unknown colored matters are produced. At any rate $\varepsilon$ monoDNP-lysine seems to be quite stable against light and all of the $\alpha$-DNP-amino acids are photosensitive.

We compared true photodecomposition velocities of DNP-alanine, -glycine, -valine, and -aspartic acid by measuring remaining DNPamino acids after being purified by chromatography using silicagel as absorbents. The results are shown in Fig. 2.

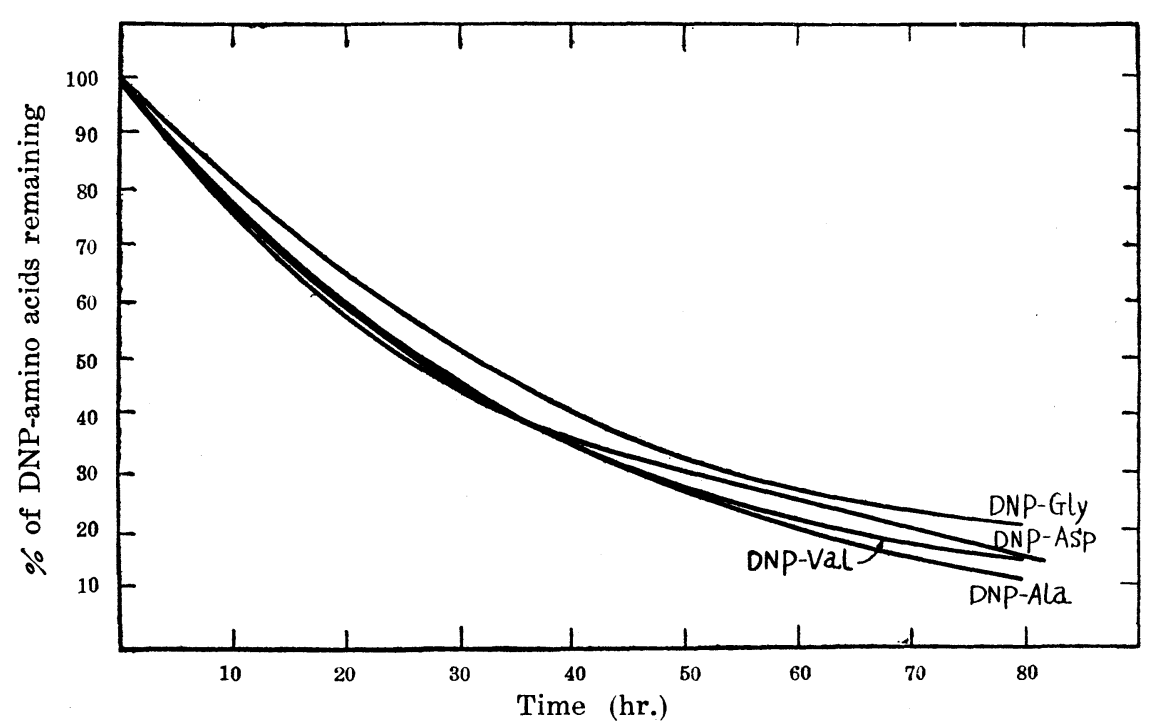

Fig. 2. Rate of photolysis of $0.1 \mathrm{mmol}$ solution of DNP-amino acids as mentioned by color densities of remaining DNP-amino acids

As is seen from Fig. 2, no marked differences between decomposition rates of the above described four DNP-amino acids were observed.

\section{References}

1) F. Sanger: Biochem. J., 39, 507 (1945).

2) F. Sanger: Biochem. J., 45, 563 (1949).

3) S. Blackburn: Biochem. J., 45, 579 (1949).

4) G. L. Mills : Biochem. J., 50, 707 (1952). 